\title{
Preventing Preterm Birth with Progesterone in Women with a Short Cervical Length from a Low- Risk Population: A Multicenter Double-Blind Placebo-Controlled Randomized Trial
}

Melanie A. van Os, MD ${ }^{1} \quad$ A. Jeanine van der Ven, RM, MSc ${ }^{2} \quad$ C. Emily Kleinrouweler, MD, $\mathrm{PhD}^{2}$

Ewoud Schuit, $\mathrm{PhD}^{2,3,4}$ Brenda M. Kazemier, MD, MSc ${ }^{2}$ Corine J. Verhoeven, PhD, $\mathrm{RM}^{5,6}$

Esteriek de Miranda, PhD, RM ${ }^{2}$ Aleid G. van Wassenaer-Leemhuis, MD, $\mathrm{PhD}^{7}$

J. Marko Sikkema, MD, PhD ${ }^{8}$ Mallory D. Woiski, MD ${ }^{9}$ Patrick M. Bossuyt, PhD ${ }^{10}$ Eva Pajkrt, MD, PhD ${ }^{2}$

Christianne J. M. de Groot, MD, PhD ${ }^{1}$ Ben Willem J. Mol, MD, PhD ${ }^{11}$ Monique C. Haak, MD, PhD ${ }^{12}$

1 Department of Obstetrics and Gynecology, VU University Medical Center, Amsterdam, The Netherlands

${ }^{2}$ Department of Obstetrics and Gynecology, Academic Medical Center, Amsterdam, The Netherlands

3 Julius Center for Health Sciences and Primary Care, University Medical Center, Utrecht, The Netherlands

${ }^{4}$ Stanford Prevention Research Center, Stanford University, Stanford, California

${ }^{5}$ Department of Obstetrics and Gynecology, Máxima Medisch Centrum, Veldhoven, The Netherlands

6 Department of Midwifery Science, AVAG/EMGO Institute for Health and Care Research, VU University Medical Center, Amsterdam, The Netherlands

7 Department of Neonatology, Emma Children's Hospital, Academic Medical Center, Amsterdam, The Netherlands

${ }^{8}$ Department of Obstetrics and Gynecology, ZGT, Almelo, The Netherlands

${ }^{9}$ Department of Obstetrics and Gynecology, Radboud University, Nijmegen, The Netherlands

10 Department of Clinical Epidemiology, Academic Medical Center, Amsterdam, The Netherlands

${ }^{11}$ The Robinson Institute, School of Paediatrics and Reproductive Health, University of Adelaide, Adelaide, Australia

12 Department of Obstetrics, Leiden University Medical Center, Leiden, The Netherlands

Am J Perinatol 2015;32:993-1000.
Address for correspondence Melanie A. van Os, MD, Department Obstetrics and Gynecology, VU University Medical Center, 8F, Boelelaan 1117, 1084 HV, Amsterdam, The Netherlands (e-mail: M.vanos@vumc.nl).

\begin{abstract}
Keywords

- cervical length

- preterm birth

- progesterone

- neonatal outcome

Objective The objective of this study was to evaluate the effectiveness of vaginal progesterone in reducing adverse neonatal outcome due to preterm birth (PTB) in lowrisk pregnant women with a short cervical length $(\mathrm{CL})$.

Study Design Women with a singleton pregnancy without a history of PTB underwent $\mathrm{CL}$ measurement at 18 to 22 weeks. Women with a $\mathrm{CL} \leq 30 \mathrm{~mm}$ received vaginal progesterone or placebo. Primary outcome was adverse neonatal outcome, defined as a composite of respiratory distress syndrome, bronchopulmonary dysplasia, intracerebral hemorrhage $>$ grade II, necrotizing enterocolitis $>$ stage 1 , proven sepsis, or death before discharge. Secondary outcomes included time to delivery, PTB before 32, 34, and 37 weeks of gestation. Analysis was by intention to treat.
\end{abstract}

received

November 19, 2014

accepted after revision

January 23, 2015

published online

March 4, 2015
Copyright $\odot 2015$ by Thieme Medical Publishers, Inc., 333 Seventh Avenue, New York, NY 10001, USA.

Tel: +1(212) 584-4662.
DOI http://dx.doi.org/ 10.1055/s-0035-1547327. ISSN 0735-1631. 
Results Between 2009 and 2013, 20,234 women were screened. A CL of 30 mm or less was seen in 375 women (1.8\%). In 151 women, a $\mathrm{CL} \leq 30 \mathrm{~mm}$ was confirmed with a second measurement and 80 of these women agreed to participate in the trial. We randomly allocated 41 women to progesterone and 39 to placebo. Adverse neonatal outcomes occurred in two (5.0\%) women in the progesterone and in four $(11 \%)$ women in the control group (relative risk [RR], 0.47; 95\% confidence interval [Cl], 0.09-2.4). The use of progesterone resulted in a nonsignificant reduction of PTB $<32$ weeks ( 2.0 vs. 8.0\%; RR, $0.33 ; 95 \% \mathrm{Cl}, 0.04-3.0$ ) and $<34$ weeks (7.0 vs. $10 \%$; RR, $0.73 ; 95 \% \mathrm{Cl}, 0.18$ 3.1) but not on PTB < 37 weeks ( 15 vs. $13 \%$; RR, 1.2; $95 \% \mathrm{Cl}, 0.39-3.5$ ).

Conclusion In women with a short cervix, who are otherwise low risk, we could not show a significant benefit of progesterone in reducing adverse neonatal outcome and PTB.

Spontaneous preterm delivery is the most important cause of perinatal mortality in the Western world. ${ }^{1}$ Although women with a previous preterm birth (PTB) and women with a multiple gestation are at the highest risk of $\mathrm{PTB},{ }^{2-4}$ the majority of spontaneous PTBs occur in low-risk women. ${ }^{5}$ Interventions for threatened $\mathrm{PTB}$, such as tocolysis, bed rest, or placement of a cervical cerclage, have shown limited effectiveness. $^{6-8}$ Only antenatal administration of corticosteroids improved neonatal outcome. ${ }^{9}$ Consequently, prevention of (the onset of) PTB is essential.

Identification of low-risk women who will deliver prematurely is crucial in the development of preventive strategies. One of the best predictors in this group is cervical length $(\mathrm{CL})$, measured by transvaginal ultrasound at 20 to 22 weeks of gestation. ${ }^{10-12}$ Recently, published studies showed promising results for progesterone in the prevention of РTB. ${ }^{13,14}$ As these studies evaluated the effect of progesterone in an unselected population with a combination of high-risk and low-risk women, the effectiveness of vaginal progesterone in a population with strictly low-risk women remains unknown. Previous studies did not show maternal or fetal side effects of progesterone. ${ }^{15-17}$ We designed a multicenter study in lowrisk women to evaluate the ability of CL measurement to detect those at increased risk for PTB. Women with a short CL were asked to participate in a randomized clinical trial to evaluate whether subsequent progesterone treatment is effective. ${ }^{18}$ We defined low risk for PTB as women who did not have a history of PTB before 34 weeks of gestation. Here, we report the results of the trial, and results of the cohort will be published separately.

\section{Materials and Methods}

A multicenter double-blind placebo-controlled randomized clinical trial was performed within the Dutch Obstetric Research Consortium, which is a collaborative research effort of obstetric practices in the Netherlands. The present study was conducted in 7 university hospitals, 23 general hospitals, 29 ultrasound centers, and 160 midwifery practices. The trial was approved by the Medical Ethical Committee of the
Academic Medical Center, Amsterdam, the Netherlands (MEC AMC 08-328).

Women with a low-risk singleton pregnancy and a $\mathrm{CL}$ $\leq 30 \mathrm{~mm}$ were included in our study. Low-risk pregnancy was defined as nulliparous, or multiparous women without a history of spontaneous PTB $<34$ weeks of gestation. Exclusion criteria were age $<18$ years, cervical cerclage, previous $\mathrm{PTB}<34$ weeks, preterm labor, or known congenital malformations.

$\mathrm{CL}$ was measured during the standard anomaly scan at 18 to 22 weeks of gestation using transvaginal ultrasound. The image had to display an empty bladder, full length of the endocervical mucosa in an exact mid-sagittal plane of the cervix, and an equal thickness of anterior and posterior cervical wall. The calipers were placed at the distance between the triangular area of echo density at the external os and the v-shaped notch at the internal os. When there was a curved aspect of the endocervical mucosa, sonographers were allowed to place the calipers on the external and internal os as described before and make a straight or a curved line between the calipers. ${ }^{19,20}$ In the case of funneling, the funnel itself was not included in the measurement. The ultrasonographers were instructed to measure the CL approximately 3 minutes after the insertion of the vaginal probe and to document the shortest measurement. All participating sonographers were experienced, capable to perform standard anomaly scans, and completed an e-learning module on CL measurement before participation in this study.

Short CL was defined as a $\mathrm{CL} \leq 30 \mathrm{~mm}$. To ensure the quality of the measurement, women with a $\mathrm{CL} \leq 30 \mathrm{~mm}$ at the initial scan were scheduled for a second assessment within 2 weeks after the first measurement. Subsequently, only women with two measurements $\leq 30 \mathrm{~mm}$ were eligible for the trial.

Eligible women were informed by a gynecologist, a midwife, or one of the trial's research nurses and had 5 days to consider participation in the trial. After obtaining written informed consent, a web-based randomization was performed.

Eligible women who declined participation in the trial received routine obstetric care, without the prescription of progesterone. 


\section{Intervention}

Each study participant received a blister pack, which contained capsules with $200 \mathrm{mg}$ micronized progesterone (Utrogestan, Besins International Belgium) or identical-appearing capsules of placebo (Medicaps).

The capsules were self-administered vaginally on a daily basis between 22 and 34 weeks of gestational age. Label codes indicating progesterone or placebo were only known in the central pharmacy. Disclosure of the codes was done after data on primary outcome were collected, 10 weeks after the last participant had delivered. Baseline characteristics were recorded after randomization. All participants kept a medication diary, which was collected after the delivery.

\section{Outcome Measures}

The primary outcome measure was a composite of adverse neonatal outcome until 10 weeks after the expected date of delivery, containing the following components: respiratory distress syndrome (RDS), bronchopulmonary dysplasia (BPD), intracerebral hemorrhage $>$ grade II, necrotizing enterocolitis (NEC) > stage 1, proven sepsis, and death before discharge. Intracerebral hemorrhage $>$ grade II and NEC $>$ stage 1 were defined according to previously described classifications. ${ }^{21,22}$ RDS was defined as need for artificial ventilation and an X-ray, meeting RDS criteria. ${ }^{23}$ BPD was defined as need for supplemental oxygen during at least 28 days after birth.

Secondary outcome measures were time to delivery; birth before 32, 34, and 37 weeks; days of admission in neonatal intensive care unit; and days of maternal hospitalization for threatened preterm labor.

\section{Sample Size Calculation}

We anticipated an adverse neonatal outcome in $14 \%$ of the pregnancies in which CL was $<15 \mathrm{~mm}$, and in $3 \%$ of the pregnancies with a CL between 15 and $30 \mathrm{~mm} .{ }^{13}$ We assumed $1.7 \%$ of the women would have a $\mathrm{CL}<15 \mathrm{~mm}$, and $8.3 \%$ of the women would have a CL between 15 and $30 \mathrm{~mm}$ based on the study by Fonseca et al. ${ }^{13}$ The probability of adverse neonatal outcome in women with a cervix shorter or equal to $30 \mathrm{~mm}$ was assumed to be $5.0 \%$ in the control group. A reduction to $2.5 \%$ was expected after the use of progesterone. With the use of a two-sided test with an $\alpha$ of 0.05 and a $\beta$ of $0.2,1,920$ women (960 per arm) were needed in this study.

As we expected that $10 \%$ of the women would have a cervix $\leq 30 \mathrm{~mm}$ with the assumption that $50 \%$ of the eligible women would participate, we planned to screen 40,000 women.

\section{Statistical Analysis}

The analysis was performed according to the intention-totreat principle. The effectiveness of progesterone was expressed as the ratio of the primary outcome rates, as a relative risk (RR) with a $95 \%$ confidence interval $(\mathrm{CI})$, calculated using a log-binomial mixed model. Differences in time to delivery were evaluated by Kaplan-Meier estimates and tested with a log-rank test. Differences in continuous outcomes between both strategies were assessed using a linear mixed model, or a linear quantile mixed model.
Due to an unexpected low prevalence of women with a short cervix, the study was stopped early after enrolling 80 of the 1,920 planned women, after 4 years and evaluating 20,234 women for eligibility.

\section{Role of the Funding Source}

The study was funded by the Healthcare Efficiency program from ZonMw, the Dutch Organization for Health Research and Development (project number 50-501 10-96-530). The funder had no role in study design; collection, analysis, and interpretation of data; writing of the report; or the decision to submit the article for publication. The investigators had full access to all the data in the study and had final responsibility for the decision to submit the article for publication.

\section{Results}

In the study period (from November 1, 2009, to August 1, 2013), 20,234 women were screened for a short cervix. ACL of $30 \mathrm{~mm}$ or less was seen in 375 women (1.8\%). In 151 women, a $\mathrm{CL} \leq 30 \mathrm{~mm}$ was confirmed with a second measurement (40\%). Of the 224 women without a confirmed short cervix, 121 women (32\%) had a CL of more than $30 \mathrm{~mm}$ at the second measurement, whereas 103 women (28\%) refused to undergo a second CL measurement, the reason for their decline was not collected. Of the 151 women with a confirmed short cervix, 80 agreed to participate in the trial of which 41 were randomly allocated to progesterone and 39 to placebo (-Fig. 1). The earliest gestational age for randomization was $19+1$ weeks of gestation and the latest was $25+5$ weeks of gestation. Baseline maternal characteristics between the two groups were comparable ( - Table $\mathbf{1}$ ).

All 80 pregnancies ended in a live birth, and the primary outcome was available in all women. Adverse neonatal outcome was observed in 2 of the 41 women (5.0\%) in the progesterone group and in 4 of the $39(11 \%)$ in the placebo group (RR, 0.47; 95\% CI, 0.092-2.4).

There were two cases of RDS in both groups (2 [5.0\%] vs. 2 [6.0\%]; RR, 0.92; 95\% CI, 0.14-6.21), while none of the neonates suffered from intracerebral hemorrhage $>$ grade II, NEC > stage 1 , and/or proven sepsis. BPD was seen once in

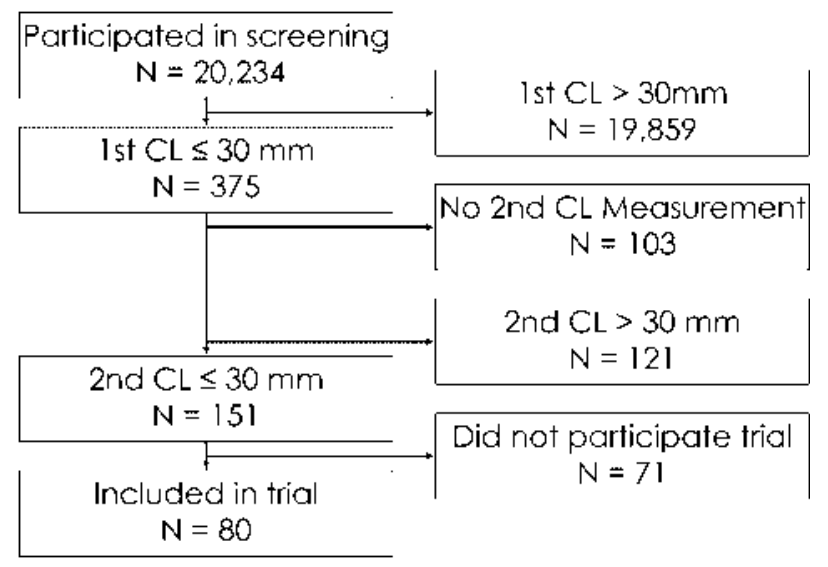

Fig. 1 Flow diagram detailing patient enrollment. 
Table 1 Baseline characteristics of the participants in the progesterone and placebo group

\begin{tabular}{|c|c|c|}
\hline Maternal characteristic & Progesterone $(N=41)$ & Placebo $(N=39)$ \\
\hline Maternal age at randomization (y) & $31(5)$ & $30(5)$ \\
\hline Gestational age at randomization (wk) & $21.7(20.7-22.6)$ & $\begin{array}{l}21.6 \\
(20.9-22.7)\end{array}$ \\
\hline Cervical length (mm) & $26(23-29)$ & $27(25-28)$ \\
\hline Body mass index $\left(\mathrm{kg} / \mathrm{m}^{2}\right)$ & $23(21-25)$ & $23(22-27)$ \\
\hline \multicolumn{3}{|l|}{ Ethnic origin } \\
\hline Caucasian & $27(71 \%)$ & $26(67 \%)$ \\
\hline Higher professional education & $6(29 \%)$ & $7(39 \%)$ \\
\hline Nulliparous & $30(73 \%)$ & $25(64 \%)$ \\
\hline \multicolumn{3}{|l|}{ Obstetric history } \\
\hline Spontaneous abortion & $11(25 \%)$ & $13(33 \%)$ \\
\hline Extra uterine pregnancy & $0(0 \%)$ & $1(2 \%)$ \\
\hline Abortion & $5(10 \%)$ & $4(8 \%)$ \\
\hline Smoking during pregnancy & $8(21 \%)$ & $8(24 \%)$ \\
\hline Alcohol use during pregnancy & $1(3 \%)$ & $0(0 \%)$ \\
\hline Drug use during pregnancy & $1(3 \%)$ & $0(0 \%)$ \\
\hline \multicolumn{3}{|l|}{ Risk profile } \\
\hline DES exposure & $0(0 \%)$ & $0(0 \%)$ \\
\hline Conization or LLETZ & $5(14 \%)$ & $2(5 \%)$ \\
\hline GBS colonization & $2(6 \%)$ & $1(3 \%)$ \\
\hline Gingivitis/periodontitis & $1(3 \%)$ & $1(3 \%)$ \\
\hline Uterine anomaly & $1(2 \%)$ & $0(0 \%)$ \\
\hline Uterine surgery & $1(2 \%)$ & $0(0 \%)$ \\
\hline Bacterial vaginosis & $3(8 \%)$ & $2(6 \%)$ \\
\hline
\end{tabular}

Abbreviations: DES, diethylstilbestrol; GBS, group B streptococcus; LLETZ, large excision of the transformation zone. Note: Data are mean (standard deviation) number (\%) or median (interquartile range).

the placebo group (3.0\%). Death before discharge occurred in one child $(2.0 \%)$ in the progesterone group and two $(5.0 \%)$ in the placebo group (RR, 0.46; 95\% CI, 0.031-6.8). Death in the progesterone group was caused by extreme prematurity in combination with RDS at 24 weeks of gestational age. The two deaths in the placebo group were caused by extreme prematurity at 24 and 25 weeks of gestational age. Congenital anomalies were observed in five children (12\%) in the progesterone group and in two (5.0\%) in the placebo group (RR, $2.31 ; 95 \% \mathrm{CI}, 0.48-11.20$ ). The anomalies consisted of polydactyly, atrial septal defect, Noonan syndrome, mild hypospadias, spherocytosis, cystic fibrosis, and pes equinovarus. All neonates were treated following standard procedures; follow-up after 24 months is planned.

After birth, eight children were admitted to a neonatal intensive care unit, three (13\%) in the progesterone group, and five $(7.0 \%)$ in the placebo group (RR, 0.53; 95\% CI, 0.122.25). Days of admission ranged from 1.5 to 8 days in the progesterone group and from 4 to 31 days in the placebo group.

Progesterone led to a statistically nonsignificant prolonged time to delivery (-Fig. 2). The use of progesterone led to a nonsignificant reduction of spontaneous PTB $<32$ weeks of gestation (2.0 vs. 8.0\%; RR, 0.33; 95\% CI, 0.04-3.0) and $<34$ weeks of gestation ( 7.0 vs. $10 \%$; RR, 0.73 ; $95 \% \mathrm{CI}$, $0.18-3.1$ ) but not $<37$ weeks of gestation (15 vs. $13 \%$; RR, 1.2; 95\% CI, 0.39-3.5).

Side effects related to study treatment were reported in four (12\%) women who received vaginal progesterone compared with seven (23\%) who received placebo (RR, 0.51; 95\% CI, 0.16-1.6) (-Table 2). Eleven (27\%) women in the progesterone group and 12 (31\%) in the placebo group stopped treatment before completion. In the progesterone group, six women did not take any capsules, two used less than half of the prescribed capsules, and three stopped after using more than half of the prescribed capsules (-Table $\mathbf{2}$ ).

In the placebo group, five women did not use any medication, five used less than half of the prescribed capsules, and two stopped after using half of the prescribed capsules. In total, four medication diaries were lost to follow-up. Reported reasons for premature discontinuation of treatment were side effects, feelings of anxiety about the use of medication in pregnancy, and disagreement/nonapproval of the partner. 


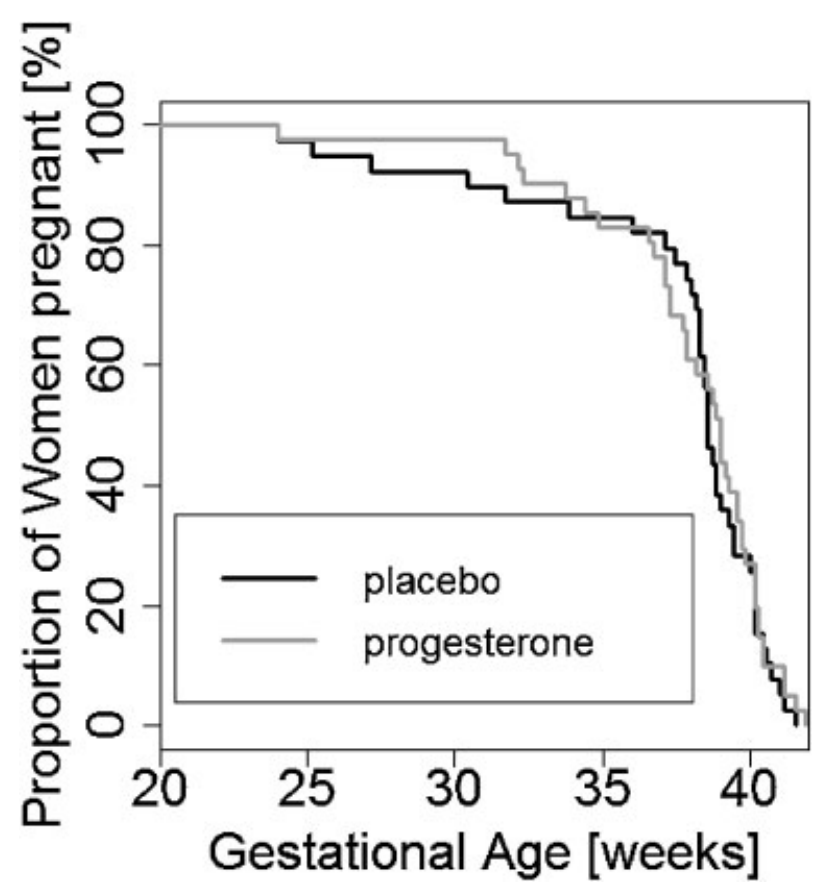

Fig. 2 Kaplan-Meier curve of the time to delivery among patients receiving vaginal progesterone compared with placebo. A nonsignificant prolongation of time to delivery in the progesterone group (log-rank test $p$-value 0.636).

None of the randomized women underwent an emergency cervical cerclage after randomization. Tocolytics were used in seven women (18\%) in the progesterone group and in four women (10\%) in the placebo group. Corticosteroids for fetal lung maturation were given to nine women $(22 \%)$ in the progesterone group and to six women $(16 \%)$ in the placebo group. No other interventions were reported.

\section{Discussion}

In this double-blind, placebo-controlled study, which was discontinued early, we evaluated the efficacy of vaginal progesterone in reducing adverse neonatal outcome through a reduction in PTB rate in women with a low-risk pregnancy and a short cervix ( $\leq 30 \mathrm{~mm}$ ). Less than $2 \%$ of all screened women had a $\mathrm{CL} \leq 30 \mathrm{~mm}$. Adverse neonatal outcome occurred less often in those treated with progesterone, but this difference was not statistically significant. Women who used progesterone had a nonsignificant longer duration until delivery with lower rates of PTB $<32$ weeks and $<34$ weeks of gestation.

The strengths of this study are that it is a multicenter, placebo-controlled, double-blind randomized trial. The placebo and vaginal progesterone capsules were identical in appearance. Furthermore, the CL measurements were performed in a true low-risk population. A strength but at the same time a limitation might have been the second CL measurement of which the aim was to ensure a high-quality measurement and true short cervix. This might have contributed to high-quality measurements, however, it resulted in less trial participants because $27 \%$ of the women who had a short cervix at the first measurement declined to have a second measurement. Moreover, one-third of the women with an initial short cervix had a longer cervix at repeat measurement. Although this might indicate a lack of test reproducibility, normal biological variation should not be excluded as a cause.

Another limitation is the compliance of the participants, in both the progesterone and the placebo group, as approximately $30 \%$ of the women did not use the prescribed medication until 34 weeks of gestation or delivery.

The results of this study, in which a combined approach of transvaginal sonographic CL measurement and subsequent administration of vaginal progesterone capsules from midtrimester pregnancy until 34 weeks of gestation to the women with a short cervix, indicate that although there were fewer adverse neonatal outcomes in the progesterone group, this trial failed to show a statistically significant benefit from vaginal progesterone in reducing PTB and adverse neonatal outcome. Given that the study was stopped early after inclusion of only 80 of the targeted 1,920 women, a beneficial effect of progesterone cannot be excluded because the needed sample size was not reached.

However, the effect of progesterone on PTB and neonatal outcome has been studied in larger studies. ${ }^{13,14,24-26}$ A reduction of PTB before 34 weeks of gestational age was found by Fonseca et al and Hassan et al who administered vaginal progesterone to women with a $\mathrm{CL}$ of, respectively, $<15 \mathrm{~mm}$ and between 10 and $20 \mathrm{~mm}$. Our study results point in the same direction, though there was no statistically significant difference. In our study, we found $1.8 \%$ of women with a $\mathrm{CL} \leq 30 \mathrm{~mm}$, which is low compared with the number of short cervices both studies found within their cutoff range, respectively. Possible explanations for this difference are that both the Fonseca and Hassan trial did not measure CL in a strictly low-risk population and used shorter CL as a cutoff. However, they did use a similar approach to identify the patients at risk by screening with transvaginal sonography to diagnose a short cervix. ${ }^{13,14}$

Grobman et $\mathrm{al}^{27}$ conducted a randomized trial among nulliparous women with a singleton gestation and mid-trimester $\mathrm{CL}<30 \mathrm{~mm}$. Weekly injections with $17-\alpha$-hydroxyprogesterone caproate or placebo did not alter the frequency of PTB $<37$ weeks of gestation or neonatal outcomes, such as in our study, there was a statistically nonsignificant reduction of early PTB $<32$ and $<34$ weeks of gestation. ${ }^{27}$ Again these results show a strong similarity to our trial results except for the fact that this trial found $10 \%$ of the measured CLs to be $30 \mathrm{~mm}$ or less, which is again substantially more than the $1.8 \%$ found in our study. This study used another dosage and type of progesterone, which might also have an effect on the outcome. Results of larger studies as; PROGRESS (progesterone after previous preterm birth for prevention of neonatal respiratory distress syndrome) and OPPTIMUM (does progesterone prophylaxis for the prevention of preterm labour improve outcome?) have to be awaited, before more definite conclusions can be drawn. ${ }^{28,29}$

Be it as it may, the number of screen positives in our population was so low that this questions the effectiveness of a screen-treat program with short cervix measurement and progesterone, as most of the PTBs that occurred in our low-risk population cohort were not identified by $\mathrm{CL}$ measurement. ${ }^{30}$ Formal cost-effectiveness analysis, also addressing the value of 
Table 2 Maternal and perinatal outcomes according to treatment group

\begin{tabular}{|c|c|c|c|}
\hline Characteristic & Progesterone $(N=41)$ & Placebo $(N=39)$ & Relative risk $(95 \% \mathrm{Cl})$ \\
\hline \multicolumn{4}{|l|}{ Neonatal outcome } \\
\hline Composite adverse neonatal outcome & $2(5 \%)$ & $4(11 \%)$ & $0.47(0.092-2.4)$ \\
\hline Respiratory distress Syndrome & $2(5 \%)$ & $2(6 \%)$ & $0.92(0.14-6.21)$ \\
\hline Bronchopulmonary dysplasia & $0(0 \%)$ & $1(3 \%)$ & NA \\
\hline Intracerebral hemorrhage grade II or worse & $0(0 \%)$ & $0(0 \%)$ & NA \\
\hline Necrotizing enterocolitis $>$ stage 1 & $0(0 \%)$ & $0(0 \%)$ & NA \\
\hline Proven sepsis & $0(0 \%)$ & $0(0 \%)$ & NA \\
\hline Death before discharge & $1(2 \%)$ & $2(5 \%)$ & $0.46(0.031-6.8)$ \\
\hline Mean birth weight $(g)$ & $3035(2580-3450)$ & $3318(2842-3606)$ & $-247(-642-147)^{a}$ \\
\hline \multicolumn{4}{|l|}{ Birth weight } \\
\hline$<2,500 \mathrm{~g}$ & $9(22 \%)$ & $8(21 \%)$ & $1.07(0.46-2.48)$ \\
\hline$<1,500 \mathrm{~g}$ & $2(5 \%)$ & $4(11 \%)$ & $0.46(0.081-2.62)$ \\
\hline Congenital anomalies & $5(12 \%)$ & $2(5 \%)$ & $2.31(0.48-11.20)$ \\
\hline 5-minute Apgar score $<7$ & $1(2 \%)$ & $3(8 \%)$ & $0.30(0.033-2.76)$ \\
\hline NICU admission & $3(7 \%)$ & $5(13 \%)$ & $0.53(0.12-2.25)$ \\
\hline Days of NICU admission for those admitted & $3(1.5-5.5)$ & $8(7-31)$ & $-5.0(-27-0.15)^{\mathrm{a}}$ \\
\hline \multicolumn{4}{|l|}{ Delivery } \\
\hline \multicolumn{4}{|l|}{ Total preterm births (wk) } \\
\hline$<37$ & $9(22 \%)$ & $7(18 \%)$ & $1.25(0.52-3.034)$ \\
\hline$<34$ & $5(12 \%)$ & $6(15 \%)$ & $0.81(0.27-2.44)$ \\
\hline$<32$ & $3(7 \%)$ & $5(13 \%)$ & $0.58(0.14-2.30)$ \\
\hline \multicolumn{4}{|l|}{ Spontaneous preterm births (wk) } \\
\hline$<37$ & $6(15 \%)$ & $5(13 \%)$ & $1.17(0.39-3.52)$ \\
\hline$<34$ & $3(7 \%)$ & $4(10 \%)$ & $0.73(0.17-3.057)$ \\
\hline$<32$ & $1(2 \%)$ & $3(8 \%)$ & $0.33(0.035-2.99)$ \\
\hline Start of labor by PPROM/SROM & $8(20 \%)$ & $13(33 \%)$ & $0.6(0.28-1.29)$ \\
\hline \multicolumn{4}{|l|}{ Labor induction } \\
\hline Fetal indication & $0(0 \%)$ & $3(38 \%)$ & NA \\
\hline Hypertensive disorders & $4(40 \%)$ & $1(12 \%)$ & $3.2(0.36-29)$ \\
\hline Post term & $1(10 \%)$ & $1(12 \%)$ & $0.80(0.050-13)$ \\
\hline Other & $5(50 \%)$ & $3(38 \%)$ & $1.3(0.32-5.6)$ \\
\hline \multicolumn{4}{|l|}{ Mode of delivery } \\
\hline Spontaneous vaginal & $32(78 \%)$ & $30(77 \%)$ & $1.0(0.61-1.7)$ \\
\hline Caesarean before labor & $5(12 \%)$ & $2(5 \%)$ & $2.4(0.50-12)$ \\
\hline Caesarean after labor & $0(0 \%)$ & $3(8 \%)$ & NA \\
\hline Operative vaginal & $4(10 \%)$ & $4(10 \%)$ & $0.98(0.26-3.6)$ \\
\hline All live births at any GA & $41(100 \%)$ & $39(100 \%)$ & NA \\
\hline Death within $24 \mathrm{~h}$ after delivery & 0 & $2(5 \%)$ & NA \\
\hline \multicolumn{4}{|l|}{ Pregnancy outcome } \\
\hline Tocolytic treatment & $7(18 \%)$ & $4(10 \%)$ & $1.8(0.54-5.9)$ \\
\hline Corticosteroids & $9(22 \%)$ & $6(16 \%)$ & $1.4(0.56-3.6)$ \\
\hline Cerclage placement & $0(0 \%)$ & $0(0 \%)$ & NA \\
\hline PPROM & $3(7 \%)$ & $5(13 \%)$ & $0.59(0.15-2.3)$ \\
\hline
\end{tabular}


Table 2 (Continued)

\begin{tabular}{|l|l|l|l|}
\hline Characteristic & Progesterone $(N=41)$ & Placebo $(N=39)$ & Relative risk (95\% CI) \\
\hline GA at PPROM (wk) & $34(33-35)$ & $31(27-34)$ & $0.46(0.11-1.9)^{\mathrm{b}}$ \\
\hline Chorioamnionitis & $1(12 \%)$ & $1(11 \%)$ & $1.1(0.083-15)$ \\
\hline Funisitis & $1(12 \%)$ & $0(0 \%)$ & NA \\
\hline Side effects medication & $4(12 \%)$ & $7(24 \%)$ & $0.51(0.16-1.61)$ \\
\hline Pain & $1(3 \%)$ & $0(0 \%)$ & NA \\
\hline Vaginal discharge & $4(12 \%)$ & $5(17 \%)$ & $0.77(0.22-2.7)$ \\
\hline Itching & $2(6 \%)$ & $3(10 \%)$ & $0.59(0.11-3.29)$ \\
\hline Local irritation & $1(3 \%)$ & $0(0 \%)$ & NA \\
\hline Redness & $0(0 \%)$ & $0(0 \%)$ & NA \\
\hline Maternal admission days for preterm labor & $6(25 \%)$ & $7(25 \%)$ & $1.03(0.39-2.70)$ \\
\hline Compliance & \multicolumn{3}{l}{} \\
\hline Used $\geq 80 \%$ of study medication & $23(57 \%)$ & $18(50 \%)$ & $27(75 \%)$ \\
\hline Used $\geq 50 \%$ of study medication & $32(80 \%)$ & & \\
\hline
\end{tabular}

Abbreviations: GA, gestational age; NA, not applicable; NICU, neonatal intensive care unit; PPROM, preterm prelabor rupture of membranes; SROM, spontaneous rupture of membranes.

a Median difference, 95\% $\mathrm{Cl}$.

bHazard ratio $95 \% \mathrm{Cl}$.

Note: Data are mean (standard deviation) number (\%) or median (interquartile range).

repeated CL measurement, is needed to address this issue. Apart from progesterone, the other intervention that should be addressed here is cervical pessary. The latter intervention, known since 1959, has recently be found to be promising in women with a short cervix. ${ }^{31,32}$

In summary, the results of this trial show no statistically significant benefit of vaginal progesterone in reducing composite adverse neonatal outcome and PTB in women with a short cervix. Our study was underpowered due to a much lower than anticipated number of women with short cervix and was stopped early because of this. Further investigation in the form of extrapolation and data pooling through metaanalysis is needed to evaluate the use of vaginal progesterone in the prevention of PTB in a low-risk population.

\section{Conflict of Interest}

Ben W. Mol has been a paid advisor of Besins Health Care.

\section{Acknowledgments}

We thank the participants, the research nurses, and midwives of our consortium; the primary care midwives and sonographers of the participating ultrasound centers along with the sonographers, residents, and obstetricians of the participating hospitals for their help with patient recruitment and data collection.

\section{References}

1 Murray CJL, Vos T, Lozano R, et al. Disability-adjusted life years (DALYs) for 291 diseases and injuries in 21 regions, 1990-2010: a systematic analysis for the Global Burden of Disease Study 2010. Lancet 2013;381(9867):628
2 Goldenberg RL, Andrews WW, Faye-Petersen O, Cliver SP, Goepfert A, Hauth JC. The Alabama Preterm Birth Project: placental histology in recurrent spontaneous and indicated preterm birth. Am J Obstet Gynecol 2006;195:792-796

3 Ananth CV, Getahun D, Peltier MR, Salihu HM, Vintzileos AM. Recurrence of spontaneous versus medically indicated preterm birth. Am J Obstet Gynecol 2006;195(3):643-650

4 Kazemier B, Buijs PE, Mignini L, de Groot CJM, Mol BW. Impact of obstetric history on the risk of spontaneous preterm birth in singleton and multiple pregnancies: a systematic review. BJOG 2014;121(10):1197-1208

5 Iams JD, Goldenberg RL, Meis PJ, et al; National Institute of Child Health and Human Development Maternal Fetal Medicine Unit Network. The length of the cervix and the risk of spontaneous premature delivery. N Engl J Med 1996;334(9):567-572

7 Sprague AE, O'Brien B, Newburn-Cook C, Heaman M, Nimrod C. Bed rest and activity restriction for women at risk for preterm birth: a survey of Canadian prenatal care providers. J Obstet Gynaecol Can 2008;30(4):317-326

8 To MS, Alfirevic Z, Heath VC, et al; Fetal Medicine Foundation Second Trimester Screening Group. Cervical cerclage for prevention of preterm delivery in women with short cervix: randomised controlled trial. Lancet 2004;363(9424):1849-1853

9 Roberts D, Dalziel S. Antenatal corticosteroids for accelerating fetal lung maturation for women at risk of preterm birth. Cochrane Database Syst Rev 2006;(3):CD004454

10 Berghella V, Tolosa JE, Kuhlman K, Weiner S, Bolognese RJ, Wapner RJ. Cervical ultrasonography compared with manual examination as a predictor of preterm delivery. Am J Obstet Gynecol 1997; 177(4):723-730

11 Heath VC, Southall TR, Souka AP, Elisseou A, Nicolaides KH. Cervical length at 23 weeks of gestation: prediction of spontaneous preterm delivery. Ultrasound Obstet Gynecol 1998;12(5): 312-317

12 Meis PJ, Klebanoff M, Thom E, et al; National Institute of Child Health and Human Development Maternal-Fetal Medicine Units Network. Prevention of recurrent preterm delivery by 17 alpha-hydroxyprogesterone caproate. N Engl J Med 2003;348(24):2379-2385 
13 Fonseca EB, Celik E, Parra M, Singh M, Nicolaides KH; Fetal Medicine Foundation Second Trimester Screening Group. Progesterone and the risk of preterm birth among women with a short cervix. N Engl J Med 2007;357(5):462-469

14 Hassan SS, Romero R, Vidyadhari D, et al; PREGNANT Trial. Vaginal progesterone reduces the rate of preterm birth in women with a sonographic short cervix: a multicenter, randomized, doubleblind, placebo-controlled trial. Ultrasound Obstet Gynecol 2011; 38(1):18-31

15 Resseguie LJ, Hick JF, Bruen JA, Noller KL, O'Fallon WM, Kurland LT. Congenital malformations among offspring exposed in utero to progestins, Olmsted County, Minnesota, 1936-1974. Fertil Steril 1985;43(4):514-519

16 Katz Z, Lancet M, Skornik J, Chemke J, Mogilner BM, Klinberg M. Teratogenicity of progestogens given during the first trimester of pregnancy. Obstet Gynecol 1985;65(6):775-780

17 Yovich JL, Turner SR, Draper R. Medroxyprogesterone acetate therapy in early pregnancy has no apparent fetal effects. Teratology $1988 ; 38(2): 135-144$

18 van Os MA, van der Ven JA, Kleinrouweler CE, et al. Preventing preterm birth with progesterone: costs and effects of screening low risk women with a singleton pregnancy for short cervical length, the Triple P study. BMC Pregnancy Childbirth 2011;11(1):77

19 To MS, Skentou C, Chan C, Zagaliki A, Nicolaides KH. Cervical assessment at the routine 23-week scan: standardizing techniques. Ultrasound Obstet Gynecol 2001;17(3):217-219

20 van Os MA, van der Ven JA, Bloemendaal PM, et al. The effect of elearning on the quality of cervical length measurements. Ultrasound Obstet Gynecol 2014

21 Papile LA, Burstein J, Burstein R, Koffler H. Incidence and evolution of subependymal and intraventricular hemorrhage: a study of infants with birth weights less than 1,500 gm. J Pediatr 1978; 92(4):529-534

22 Bell MJ, Ternberg JL, Feigin RD, et al. Neonatal necrotizing enterocolitis. Therapeutic decisions based upon clinical staging. Ann Surg $1978 ; 187(1): 1-7$

23 Giedion A, Haefliger H, Dangel P. Acute pulmonary X-ray changes in hyaline membrane disease treated with artificial ventilation and positive end-expiratory pressure (PEP). Pediatr Radiol 1973; 1(3):145-152
24 O’Brien JM, Adair CD, Lewis DF, et al. Progesterone vaginal gel for the reduction of recurrent preterm birth: primary results from a randomized, double-blind, placebo-controlled trial. Ultrasound Obstet Gynecol 2007;30(5):687-696

25 O’Brien JM, Defranco EA, Adair CD, et al; Progesterone Vaginal Gel Study Group. Effect of progesterone on cervical shortening in women at risk for preterm birth: secondary analysis from a multinational, randomized, double-blind, placebo-controlled trial. Ultrasound Obstet Gynecol 2009;34(6):653-659

26 DeFranco EA, O'Brien JM, Adair CD, et al. Vaginal progesterone is associated with a decrease in risk for early preterm birth and improved neonatal outcome in women with a short cervix: a secondary analysis from a randomized, double-blind, placebocontrolled trial. Ultrasound Obstet Gynecol 2007;30(5): 697-705

27 Grobman WA, Thom EA, Spong CY, et al; Eunice Kennedy Shriver National Institute of Child Health and Human Development Maternal-Fetal Medicine Units (MFMU) Network. 17 alpha-hydroxyprogesterone caproate to prevent prematurity in nulliparas with cervical length less than 30 mm. Am J Obstet Gynecol 2012;207(5): 390.e1-390.e8

28 Dodd JM, Crowther CA, McPhee AJ, Flenady V, Robinson JS. Progesterone after previous preterm birth for prevention of neonatal respiratory distress syndrome (PROGRESS): a randomised controlled trial. BMC Pregnancy Childbirth 2009;9:6

29 Norman JE, Shennan A, Bennett P, et al. Trial protocol OPPTIMUM - does progesterone prophylaxis for the prevention of preterm labour improve outcome? BMC Pregnancy Childbirth 2012; $12: 79$

30 van der Ven AJ, van Os MA, Kazemier BM, et al. Can mid-pregnancy cervical length identify low-risk women at increased risk for preterm birth: a national cohort study. Submitted for publication

31 Liem S, Schuit E, Hegeman M, et al. Cervical pessaries for prevention of preterm birth in women with a multiple pregnancy (ProTWIN): a multicentre, open-label randomised controlled trial. Lancet 2013;382(9901):1341-1349

32 Goya M, Pratcorona L, Merced C, et al; Pesario Cervical para Evitar Prematuridad (PECEP) Trial Group.Cervical pessary in pregnant women with a short cervix (PECEP): an open-label randomised controlled trial. Lancet 2012;379(9828):1800-1806 